\title{
The effect of mother's voice on pain and physiological parameters during arterial blood sampling in children hospitalized in PICUs
}

\author{
Mahnaz Shoghi*1, Marzieh Ahmadi2 $\measuredangle$, Mahboube Rasouli ${ }^{3} \bowtie$ \\ Author affiliations:
}

1- Associate Professor of Nursing, Nursing Care Research Center, Faculty of Nursing and midwifery, Pediatric Department. , Iran University of Medical Sciences

2- MSN, Pediatric Nursing, Faculty of Nursing and midwifery, Pediatric Department, Iran University of Medical Sciences, Tehran, Iran

3- PhD, Assistant Professor of Biostatistics, Department of Biostatistics, School of Public Health, Iran University of Medical Sciences, Tehran, Iran.

Correspondence: Mahnaz Shoghi, Associate Professor of Nursing, Nursing and Midwifery School, Shahid Yasemi Street, North Kordestan Subway, Tehran, Iran; Phone: +989123176343; E-mail address: shoghi.m@iums.ac.ir

\section{Abstract}

Introduction: Arterial blood sampling is a painful procedure, and is frequently performed in PICUs. Listening to mother's voice may be effective in reducing pain during arterial blood sampling in children. This study was aimed to determine the effect of mother's recorded voice on pain and physiological parameters during arterial blood sampling in children hospitalized in PICUs.

Methodology: This study was a single blind randomized clinical trial with crossover design. Fifty children hospitalized in PICUs participated in this study. The participants were selected through "sequential sampling" and randomly allocated into two groups; e.g., Group AB $(n=25)$ and Group BA $(n=25)$. Physiological parameters and pain in each child were measured before and during arterial blood sampling with (B) and without (A) listening to their mothers' voices with a minimum of $24 \mathrm{hrs}$ interval. To measure the pain, COMFORT pain scale was used and the physiological parameters were measured using the monitoring devices connected to the children. Data were analyzed with SPSS version 22, repeated measure test, paired and non-paired t-test, Wilcoxon and Mann-Whitney test.

Results: Means of pain scores and physiologic parameters did not show a significant difference before the intervention on the first and second day between the two groups (AB-BA). The results showed the period effect $(f=$ 0.581 and $p=0.89$ ) and carry over effect ( $f=0.055, p$-value $=0.881$ ) were not significant. Results of paired $t$-test showed that the mean pain score during arterial blood sampling with (B: $21.82 \pm 5.53$ ) and without (A: 22.40 \pm 4.76 ) listening to their mothers' voices was significantly different $(p=0.002)$. That is, with the mother's voice, the children felt a lower level of pain. The $\mathrm{SpO}_{2}$ decline during the sampling was less with the mother's voice. Additionally, the heart rate declined less during the sampling compared to the rate before the sampling with the mother's voice; still, the difference was not significant $(p>0.05)$.

Conclusion: Listening to mothers' recorded voice was effective to alleviate pain during arterial blood sampling in children hospitalized in PICUs. The use of this method to reduce pain during this painful procedure is effective even in the absence of the mother.

Key words: Pain; Mother's voice; Arterial blood sampling; Physiological indices; PICU

Citation: Shoghi M, Ahmadi M, Rasouli M. The effect of mother's voice on pain and physiological parameters during arterial blood sampling in children hospitalized in PICUs. Anaesth. pain intensive care 2021;25(1):42-49. DOI: 10.35975/apic.v25i1.1440

Received: 20 June 2020, Reviewed: 16 September 2020, Accepted: 25 November 2020 


\section{Introduction}

Pain control in children is more than providing a sense of comfort for the child. Numerous negative outcomes of inadequate pain management among children have been reported, including long-term behavioral changes, pain-perception impairment, pain-tolerance reduction, physical disability, and emotional disability. ${ }^{1}$ Loss of appetite, insomnia, malnutrition, night terrors, exacerbation of symptoms, and even death are also reported. ${ }^{2}$ Pain negatively impacts physiologic responses of nearly every body system, potentially contributing to hemodynamic, respiratory, metabolic, and neurological instability. ${ }^{3}$

Pain management is one of the main responsibilities of nurses in taking care of hospitalized children. ${ }^{4}$ However, it seems that children in PICUs frequently experience high levels of pain for diagnosis and treatment procedures. According to the evidence depending on the hospitalization days, these children experience 2-25 painful procedures (13 procedures on average) per day in PICUs. ${ }^{5}$ Evidence also have showed that the frequency and severity of the painful procedures increase as the physical and hemodynamic conditions of the children becomes worse. ${ }^{6,7}$

Arterial blood sampling is one of the most painful procedures, which is mostly done without any pain control. ${ }^{8}$ The results of a study on 100 patients in ICUs showed that this procedure is one of the main concerns of them and they believe this pain is special and different from other types of pain. ${ }^{9}$

Listening to mother's voice is one of the nonpharmacological methods used for decreasing pain in childhood especially in neonatal and infancy period. ${ }^{10}$ Listening to mother's voice during a painful procedure is not only a distraction method, but also Voice of the mother is the most peaceful and familiar voice in a child's life that is heard frequently by the child (even before birth). Mothers spend more time with their children and usually use specific sentences for Caressing and comforting their children. ${ }^{10-12}$

Evidence has shown listening to mother's voice stimulates specific regions in the brain that other sounds do not. Mother's voice increases frontal cortex activity and has more effect on behavioral and neurological responses in children. ${ }^{13}$ In fact, presence of the mother during painful procedures is more comforting for the child ${ }^{14}$ however, this is not always possible in PICUs and in some cases the mother prefers not be present during painful procedures. ${ }^{11}$

The critical condition of children in PICUs and the intense condition in the ward limits feasibility of many of non-pharmaceutical approaches such as muscle relaxation, mental imaginary and concentration. It seems listening a recorded voice of the mother is an easy and feasible option in situations that mother is absent. On the other hand, there was a lack of knowledge about effectiveness of this method in childhood. Majority of studies focused on the effect of listening to mother's voice in pain of neonatal population. ${ }^{10,15}$

And there was a need for more studies in this area. ${ }^{10}$, 16-19 Therefore, the author designed the present study aiming to determine the effect of Listening of mother's voice on pain and physiological parameters during arterial blood sampling in children hospitalized in PICUs.

\section{Methodology}

The study was a blind randomized clinical trial with a crossover design. IRCT code is: 2016011902610 4N6

Sample size: The sample size based on effect size of 0.4 with error level of $5 \%, Z \boldsymbol{\alpha} / \mathbf{2}=1.96$, test power of $80 \%, Z \beta=0.84$, was obtained equal to 25 children in each group.

The participants were selected through convenience sampling basis of inclusion criteria. Then with four blocks randomization allocated to group $\mathrm{AB}$ (first day blood sampling without mother's voice; second day sampling with mother's voice) and BA (first day blood sampling with mother's voice; second day sampling without mother's voice). Inclusion criteria were minimum consciousness level of 9 based on Glasgow scale, lack of hearing impairment, not connected to ventilator, not taking analgesic drugs three hours before sampling, not taking sedatives and anti-anxiety drugs, no developmental delay, no cognitive disease, and no neuromuscular disease such as Guillain-Barre syndrome because these condition effect on child pain response Exclusion criteria were more than one attempt for arterial blood sampling, arterial blood sampling 24hrs before the first sampling, discharge or loss of the case during the study.

Instruments: A demographical form including age, gender, hospitalization duration, use of analgesic 


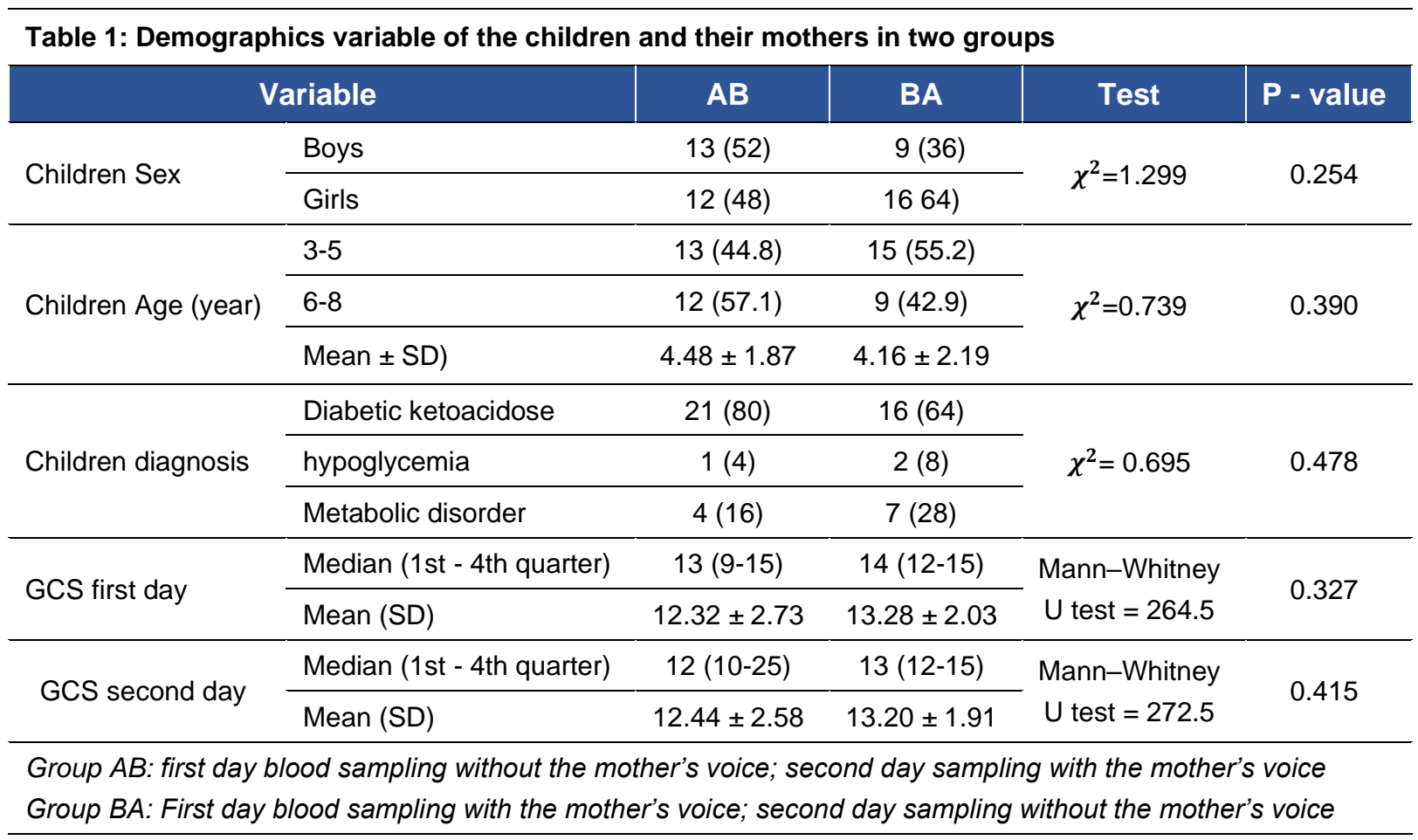

drugs, and time of administration was used. To measure the pain, COMFORT pain behavioral scale was used. The scale includes seven scale domains. Awareness (five items), restlessness (five items), respiratory response (in the case of using ventilator), crying (in the case of auto-respiration; five items), physical motion (five items), muscular tone (five items), and facial response (five items). Each item to be answered by the observer based on the observations and then the total score calculated based on that. The total score of six was interpreted as no pain and 30 as severe pain. ${ }^{20,21}$ The respiration response was only for the cases under ventilator. Physiological parameters for each child (heart rate, $\mathrm{SpO} 2$, blood pressure) was read on the monitor screen and recorded in the form for first and second days and before and during the procedure.

Intervention: After obtaining a written consent from all the mothers, each mother was asked to tell her own sentences that she usually uses to care her child and all mothers' voices were recorded. Voice recording was done in nurses' rest room in the presence of only the researcher and without any noise. In some cases, the researcher left the room to make the environment more pleasant and peaceful for the mother. After that, the recorded voice was played for each mother for conformation and they expressed their consent for using their voices.

First, the BP cuff was wrapped around the child's arm and the pulse- oximeter was fixed on the her/ his finger After 3 minutes the physiological parameters were recorded on vital sings monitor (heart rate, $\mathrm{SpO} 2$, and blood pressure) by the researcher and COMFORT pain scale was filled out ${ }^{22,23}$. Then, a pair of headphones in the shape of the Sponge Bod character was placed on the child's ears. After five minutes, the author's assistant would take the blood sample. During the sampling, (since the insertion of needle for blood suction and taking the needle out) the researcher recorded the physiological parameters and filled out the scale again.

During the first sampling procedures, the mothers' voice in group BA was played at 50-60db starting five minutes before sampling until removal of the needle and disinfecting the spot with alcohol. The experiment procedure in $A B$ was almost the same expect the fact that no voice was played for this group. In the second arterial sampling procedure (at least $24 \mathrm{hrs}$ later) the same assessment and measures were taken except that no voice was played in group BA and the subjects in group $\mathrm{AB}$ listened to their mothers' voices. 
Table 2: Pain and physiological parameters before intervention in two groups in 1st and 2nd day (Mean \pm SD)

\begin{tabular}{|c|c|c|c|c|c|}
\hline Time & Parameter & Group (AB) & Group (BA) & Test & p-vaue \\
\hline \multirow{5}{*}{$\begin{array}{l}\text { First } \\
\text { day }\end{array}$} & Systolic BP & $102.04 \pm 10.99$ & $96.32 \pm 13.42$ & $\mathrm{~T}=1.13$ & 0.264 \\
\hline & Dyastolic BP & $56.24 \pm 8.95$ & $53.88 \pm 0.916$ & $\mathrm{~T}=0.916$ & 0.364 \\
\hline & $\begin{array}{l}\text { Heart rate } \\
\text { Before }\end{array}$ & $122.48 \pm 16.08$ & $127.76 \pm 14.75$ & $\mathrm{~T}=-1.21$ & 0.232 \\
\hline & $\mathrm{O}^{2}$ saturation & $96.16 \pm 2.13$ & $95.72 \pm 2.75$ & Mann-Whitney U test $=295.5$ & 0.736 \\
\hline & Pain & $16.6 \pm 4.70$ & $17.64 \pm 3.98$ & $\mathrm{~T}=-1.021$ & 0.236 \\
\hline \multirow{5}{*}{$\begin{array}{l}\text { Second } \\
\text { day }\end{array}$} & Systolic BP & $98.20 \pm 9.24$ & $97.60 \pm 9.66$ & $\mathrm{~T}=0.224$ & 0.823 \\
\hline & Dyastolic BP & $58.28 \pm 8.77$ & $52.64 \pm 12.27$ & $\mathrm{~T}=1 / 54$ & 0.131 \\
\hline & Heart rate & $119.28 \pm 15.01$ & $119.48 \pm 12.39$ & $\mathrm{~T}=0.051$ & 0.959 \\
\hline & O2 saturation & $95.52 \pm 2.58$ & $95,24 \pm 3.55$ & Mann-Whitney $U$ test $=305$ & 0.882 \\
\hline & Pain & $15.84 \pm 4.85$ & $18.16 \pm 4.14$ & $\mathrm{~T}=0.075$ & -1.818 \\
\hline
\end{tabular}

Group AB: first day blood sampling without the mother's voice; second day sampling with the mother's voice

Group BA: First day blood sampling with the mother's voice; second day sampling without the mother's voice

It is notable that all samples were collected by the same assistant (a nurse with 10 years of work experience in PICU and a good arterial blood sampling skill) at $8 \mathrm{am}$, because at that time, the ward was quiet and the team was silent from the beginning of the intervention research. The sampling process included performing Allen's test to ensure good radial and ulnar arterial peripheral blood circulation. Then the subject's wrist was placed on an extension and the sampling area disinfected using alcohol. The sample was taken using a heparin insulin syringe at 45 degree after feeling the pubs between the two fingers. The pain scale was done by one fixed person (a PICU nurse) and the researcher recorded the physiological parameters before and during the sampling. It is

notable that none of the individuals in the sampling process, except the researcher, was informed whether or not the mother's voice is played. The sampling was according to the physician's order as a part of treatment or follow-up procedure.

Data Analysis: Mann-Whitney U test and non-paired $t$ test were used for comparison pain and physiological parameters of $\mathrm{AB}$ and $\mathrm{BA}$ group in first and second day. period effect or carry over effect, general linear models (GLMs) were used. To analyze and compare the differences in physiological variables and pain before and during arterial blood sampling,

\section{Results}

Totally, 50 children aging $4.48 \pm 1.78$ (Group BA) and $4.16 \pm 2.19$ (Group AB) took part in the study. There was no significant difference between the two groups in terms of age $(p=0.441)$ and consciousness level in two days ( $p=0.327, p=0.415$ ). The demographics of the two groups is listed in Table 1.

T-test and Mann-Whitney test showed that there was no significant difference in pain and physiological variables before intervention between the two groups $(\mathrm{BA}, \mathrm{AB})$ on the first and second days of taking atrial blood sampling (Table 2).

The results showed that period effect ( $f=0.581$ and $p$ $=0.89$ ) and carry over effect ( $\mathrm{f}=0.055$, $\mathrm{p}$-value $=$ 0.881) were not significant. So, paired t-test and Wisconsin test used for comparison of children pain and physiological parameters in two situations (A-B). Results showed that the mean pain score during arterial blood sampling with (B: $21.82 \pm 5.53$ ) and without $(\mathrm{A}: 22.40 \pm 4.76)$ listening to their mother voices was significantly different $(p=0.002)$. That is, 


\begin{tabular}{|c|c|c|c|c|c|c|}
\hline \multirow[b]{2}{*}{ Variable } & \multicolumn{2}{|c|}{$\begin{array}{l}\text { Without the mother's } \\
\text { voice }\end{array}$} & \multicolumn{2}{|c|}{ With the mother's voice } & \multirow[b]{2}{*}{$\begin{array}{l}\text { Statistical } \\
\text { Test }\end{array}$} & \multirow[b]{2}{*}{ p-value } \\
\hline & $\begin{array}{c}\text { Before } \\
\text { arterial } \\
\text { blood } \\
\text { sampling }\end{array}$ & $\begin{array}{c}\text { During } \\
\text { arterial } \\
\text { blood } \\
\text { sampling }\end{array}$ & $\begin{array}{c}\text { Before } \\
\text { arterial blood } \\
\text { sampling }\end{array}$ & $\begin{array}{l}\text { During } \\
\text { arterial blood } \\
\text { sampling }\end{array}$ & & \\
\hline Systolic BP & $\begin{array}{l}99.82 \pm \\
10.48\end{array}$ & $99.94 \pm 9.93$ & $97.26 \pm 11.44$ & $97.28 \pm 10.26$ & ${ }^{++}-0.158$ & 0.874 \\
\hline DiastolicBP & $56.08 \pm 9.21$ & $55.88 \pm 9.84$ & $54.94 \pm 10.71$ & $56.78 \pm 10.20$ & ${ }^{++}-1.5787$ & 0.113 \\
\hline HR & $\begin{array}{l}120.98 \pm \\
14.28\end{array}$ & $\begin{array}{l}146.20 \pm \\
15.45\end{array}$ & $\begin{array}{l}123.52 \pm \\
15.33\end{array}$ & $\begin{array}{l}146.62 \pm \\
16.36\end{array}$ & ${ }^{++}-1.227$ & 0.227 \\
\hline $\begin{array}{l}\mathrm{O} 2 \\
\text { saturation }\end{array}$ & $95.70 \pm 2.94$ & $94.16 \pm 3.58$ & $95.62 \pm 2.64$ & $93.94 \pm 3.63$ & ${ }^{++}-0.410$ & 0.967 \\
\hline Pain & $16.90 \pm 4.38$ & $22.40 \pm 4.76$ & $17.00 \pm 4.62$ & $21.82 \pm 5.53$ & +3.195 & ${ }^{*} 0.002$ \\
\hline
\end{tabular}

+ paired $t$-test ++ Wilcoxon test

with the mother's voice, the children felt a lower level of pain. According to Results of Wilcoxon test the SpO2 decline during the sampling was less with the mother's voice. Additionally, the heart rate declined less during the sampling compared to the rate before the sampling with the mother's voice; still, the difference was not significant $(\mathrm{p}>0.05)$ (Table 3$)$.

\section{Discussion}

The aim of this study was to determine the effects of listening to mother's voice on pain and physiological parameters during arterial blood sampling in children hospitalized in PICUs. According to the results, the mean score of pain in the two groups (with and without the mother's voice) increased by six point during the atrial blood sampling in comparison with when there is no such a thing available. Results consistent with the evidences showed children experienced high level of pain during arterial blood sampling. ${ }^{8,24}$

The mean pain score in children experiencing the two situations (with and without mother's voice) during arterial blood sampling was significantly different. The mean score of pain during arterial blood sampling with mother's voice (during the procedure) had a lower increase compared with taking arterial blood sampling without listening to their mother's voice and this difference between the two situations was significant. Studies have tried out several ways and methods to relieve pain in children.
These studies were generally done in situations such as vaccinations, intramuscular (IM) injections and blood collecting. However, limited studies were done to relieve pain during painful procedures for children in PICUs. In the other hand, more studies about the effect of mother's voice on procedural pain is done in neonatal period. Considering the difference between neonatal period and childhood, results of the studies including our study showed listening to mother's voice is effective in decreasing pain response during atrial

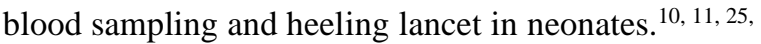
26 Some studies on children and adults also confirms our results, listening to a pleasant music is effective in decreasing pain during different painful procedures such as dressing change and intubation. ${ }^{27,28}$

The physiological parameters in children with and without listening to mother's voice before and during the procedure were not significantly different. Only $\mathrm{SpO} 2$ and heart rate were trivially lower while listening to mother's voice compared with the situation without mother's voice. The children who listened their mothers' voices had a less increase of heart rate and decline of $\mathrm{SpO} 2$; although the difference between the two groups was not significant. Stability of the physiological condition has been reported by other studies on infants and children while listening to mother's voice. ${ }^{11,29,30}$ However, review studies have emphasized that physiological parameter changes are not reliable indicators of judgment about intensity of pain. Physiological parameters are affected by several 
factors such as age, gender, emotions, medicines, and environment atmosphere. It is important to have a deeper insight into the basic physiological parameters to make a judgment about the changes in them. ${ }^{31,32}$

During the course of childhood, many children will need to undergo a medical procedure special during hospitalization in PICUs. Venous cannulation, lumbar puncture, taking $\mathrm{ABG}$, cleaning a wound or removing sutures are example of them. Children exposed to painful procedure may feel high stress and anxiety level and this can cause both short-term and long-term different effects on children (Lisi et al. 2013; Hooke et al. 2002; Twycross and Finley, 2013; Oakes et al., 2008). It is very important to reduce pain level to prevent children facing high stress in such situations. According to some studies, letting children listen to their mothers' voices during pain, the procedure in PICU can be used to relieve pain.

Doubtlessly, choosing the proper non-pharmaceutical methods for decreasing pain are depended on the severity of procedural pain with considering the child age and feasibility of method. ${ }^{33}$ Non-pharmaceutical methods are more effective on mild or moderate pain and in intensive pain using them along with analgesics are recommended. As studies have shown, listening to mother's voice decreases the mean score of pain; however according to results of our study, given the mean score pain, the children still experienced significant pain during atrial blood sampling even when they listened to their mother's voice. May be using pharmaceutical approaches is necessary along with using mother's voice during arterial blood sampling. ${ }^{34}$

It seems that children's age, the kind of painful procedure, the timing of the procedure are all important factors that should be considered for making a decision on selecting a good analgesic method. Mother's voice is more than a distraction method for infants and young children, and using it can help decrease pain and increase calmness in children during ABGs. But considering our results using this method alone isn't enough for decreasing pain during taking ABGs. ${ }^{13,19}$

Pain control and ensuring comfort of patients is one of the main responsibilities of nurses and given the special condition of PICUs and the necessity of frequent and painful therapeutic and diagnostic procedures, pain control for children in PICUs is highly important.

Presence of mother for supporting the child during painful procedures is the best choice for decreasing anxiety, pain and increasing collaboration of child with health care provider's team. But this situation in many cases is not possible in PICU ward. Based on our results, listening to mother's voice during arterial blood sampling can be a good alternative way in these situations.

Nurses in PICUs need to be highly sensitive to this issue and avoid unnecessary painful procedures. Using pharmaceutical and non-pharmaceutical approaches like playing the mother's voice to control pain in children during painful procedures in situations that mother is absence is recommended.

Considering the results of this study, assessment effect of combination methods such as mother's voice along with other biological-behavioral methods like massage and aromatherapy in PICUs is recommend. Assessment of the effect of mother's voice on pain during the arterial blood sampling in intubated children is also recommend. Moreover, it is highly recommended to study comparison of the effects of mother's voice with other hearing distraction methods such as another person's caressing voice (not the mother) or Playing one sound for all children.

\section{Conclusion}

A mother's voice can be used as a technique of distraction and calming down the pain for children hospitalized and treated in PICUs. Moreover, trying to do new studies by using this method can be very useful for judging its effectiveness in PICUs

\section{Limitation}

The noises in PICUs including different alarm sounds and the crowd in the space during pain assessment in particular are some of the limitations of this study. However, the research team tried to create an identical and peaceful environment for the cases to be isolated from the environmental stimulators. Still, controlling all the environmental variables was not possible and this limitation may affect the pain response of these children. Controlling all variables may affect the pain response and changing physiological parameters was not possible. 


\section{Acknowledgements}

We would like to thank all the participants and the research centers of Hazrat Rasul Akram Hospital for their cooperation in this study. Ethics Committee of Iran University of Medical sciences and IRAN University of medical science for supporting us. Ethical code was IR.IUMS.REC.1397.701 and IRCT code: IRCT20160119026104N6

\section{Conflict of interest}

Authors declare no conflict of interest.

\section{Authors' contribution}

MS: Write first draft of article, data collection supervisor

MA: Data collection, Manuscript editing

MR: Data analysis and methodology supervisor

\section{References}

1. Hermann C, Hohmeister J, Demirakça S, Zohsel K, Flor $\mathrm{H}$. Long-term alteration of pain sensitivity in school-aged children with early pain experiences. Pain. 2006;125(3):27885. [PubMed] DOI: $10.1016 /$ i.pain.2006.08.026

2. Evans S, Djilas V, Seidman LC, Zeltzer LK, Tsao JC. Sleep quality, affect ,pain, and disability in children with chronic pain: is affect a mediator or moderator? J Pain. 2017;18(9):1087-95. [PubMed] DOI: 10.1016/i.jpain.2017.04.007

3. Brand K, Al-Rais A. Pain assessment in children. Anaesth Intens Care Med. 2019;20(6):314-7. DOI: 10.1016/..mpaic.2019.03.003

4. Andersen RD, Nakstad B, Jylli L, Campbell-Yeo M, Anderzen-Carlsson A. The Complexities of Nurses' Pain Assessment in Hospitalized Preverbal Children. Pain Manag Nurs. 2019 Aug;20(4):337-344. [PubMed] DOl: 10.1016/i.pmn.2018.11.060

5. Baarslag MA, Jhingoer S, Ista E, Allegaert K, Tibboel D, van Dijk M. How often do we perform painful and stressful procedures in the paediatric intensive care unit? A prospective observational study. Aust Crit Care. 2019 Jan;32(1):4-10. [PubMed] DOI: 10.1016/j.aucc.2018.04.003

6. Santos RPD, Garros D, Carnevale F. Difficult decisions in pediatric practice and moral distress in the intensive care unit. Rev Bras Ter Intensiva. 2018 Apr-Jun;30(2):226-232. [PubMed] DOI: 10.5935/0103-507X.20180039

7. Ramelet AS, Abu-Saad HH, Rees N, McDonald S. The challenges of pain measurement in critically ill young children: a comprehensive review. Aust Crit Care. 2004 Feb;17(1):33-45. [PubMed] DOI: 10.1016/s10367314(05)80048-7
8. Ballesteros-Peña $\mathrm{S}$, Vallejo-De la Hoz G, FernándezAedo I; en representación del grupo de trabajo DIASURE. Pain scores for intravenous cannulation and arterial blood gas test among emergency department patients. Enferm Clin. 2018 Nov-Dec;28(6):359-364. [PubMed] DOI: 10.1016/.i.enfcli.2017.11.002

9. Hudson TL, Dukes SF, Reilly K. Use of local anesthesia for arterial punctures. Am J Crit Care. 2006 Nov;15(6):595-9. [PubMed]

10. Azarmnejad E, Sarhangi F, Javadi M, Rejeh N. The Effect of Mother's Voice on Arterial Blood Sampling Induced Pain in Neonates Hospitalized in Neonate Intensive Care Unit. Glob J Health Sci. 2015 Apr 19;7(6):198-204. [PubMed] DOI: 10.5539/gihs.v7n6p198

11. Erdoğan C, Turan T, Pınar B. The effect of maternal voice for procedural pain in paediatric intensive care unit: $A$ randomised controlled trial. Intensive Crit Care Nurs. 2020 Feb;56:102767. [PubMed] DOI: 10.1016/i.iccn.2019.102767

12. Babaei K, Alhani F, Khaleghipour M. Effect of Mother's Voice on Postoperative Pain Pediatric in Tonsillectomy Surgery. JPEN. 2016; 3 (2) :51-56. [Free Full Text]

13. Song SY, Kwak SG, Kim E. Effect of a mother's recorded voice on emergence from general anesthesia in pediatric patients: study protocol for a randomized controlled trial. Trials. 2017;18(1):430 .[PubMed] DOI: 10.1186/s13063-017-2164-4

14. Bai J, Swanson KM, Santacroce SJ. Observational coding systems of parent-child interactions during painful procedures: A systematic review. Pain Pract. 2018;18(1):130-45. [PubMed] DOI: 10.1111/papr.12588

15. Esfahani MS, Sheykhi S, Abdeyazdan Z, Jodakee M, Boroumandfar K. A comparative study on vaccination pain in the methods of massage therapy and mothers' breast feeding during injection of infants referring to Navabsafavi Health Care Center in Isfahan. Iran J Nurs Midwifery Res. 2013 Nov;18(6):494-8. [PubMed]

16. Johnston CC, Filion F, Nuyt AM. Recorded maternal voice for preterm neonates undergoing heel lance. Adv Neonatal Care. 2007 Oct;7(5):258-66. [PubMed] DOI: 10.1097/01.ANC.0000296634.26669.13

17. Birnie KA, Noel M, Parker JA, Chambers CT, Uman LS Kisely SR, et al. Systematic review and meta-analysis of distraction and hypnosis for needle-related pain and distress in children and adolescents. J Pediatr Psychol. 2014;39(8):783-808. [PubMed] DOI: 10.1093/jpepsy/jsu029

18. Ismail $A$. The challenges of providing effective pain management for children in the pediatric intensive care unit. Pain Manag Nurs. 2016 Dec;17(6):372-383. [PubMed] DOI: 10.1016/.jpmn.2016.08.005

19. Tschiedel E, Heck V, Felderhoff-Mueser U, DohnaSchwake $C$. The influence of parents' voice on the consumption of propofol for pediatric procedural sedation-a randomized controlled trial. Paediatr Anaesth. 2017 Apr;27(4):394-398. [PubMed] DOI: 10.1111/pan.13078

20. Ambuel B, Hamlett KW, Marx CM, Blumer JL. Assessing distress in pediatric intensive care environments the COMFORT scale. J Pediatr Psychol. 1992 Feb;17(1):95109. [PubMed] DOI: $10.1093 /$ jpepsy/17.1.95 
21. Ista $E$, van Dijk M, Tibboel D, de Hoog M. Assessment of sedation levels in pediatric intensive care patients can be improved by using the COMFORT "behavior" scale. Pediatr Crit Care Med. 2005 Jan;6(1):58-63. [PubMed] DOI: 10.1097/01.PCC. $0000149318.40279 .1 \mathrm{~A}$

22. Bai J, Hsu L, Tang Y, van Dijk M. Validation of the COMFORT Behavior scale and the FLACC scale for pain assessment in Chinese children after cardiac surgery. Pain Manag Nurs. 2012 Mar;13(1):18-26. [PubMed] DOI: 10.1016/j.pmn.2010.07.002

23. Abou Elella R, Adalaty H, Koay $\mathrm{YN}$, Mokrusova P, Theresa M, Male B, et al. The efficacy of the COMFORT score and pain management protocol in ventilated pediatric patients following cardiac surgery. Int J Pediatr Adolesc Med. 2015 Sep-Dec;2(3-4):123-127. [PubMed] DOI: 10.1016/j.ijpam.2015.11.001

24. Puntillo KA. Procedural pain in intensive care: translating awareness into practice. SAGE Publications Sage UK: London, England; 2016.

25. Chirico G, Cabano R, Villa G, Bigogno A, Ardesi M, Dioni $E$. Randomised study showed that recorded maternal voices reduced pain in preterm infants undergoing heel lance procedures in a neonatal intensive care unit. Acta Paediatr. 2017 Oct;106(10):1564-1568. [PubMed] DOI: 10.1111/apa.13944

26. Alhani F. The effects of maternal voice on anxiety and physiologic parameters among children undergoing tonsillectomy. 2018. [Free Full Text]

27. Liu MH, Zhu LH, Peng JX, Zhang XP, Xiao ZH, Liu QJ, et al. Effect of Personalized Music Intervention in
Mechanically Ventilated Children in the PICU: A Pilot Study. Pediatr Crit Care Med. 2020 Jan;21(1):e8-e14. [PubMed] DOI: $10.1097 / P C C .0000000000002159$

28. Benkovitz D, Pasek T, Miedel S. A supportive harmony: Music therapy for complex painful dressing changes. Ped Pain Letter. 2012;14:34-38. [Free Full Text]

29. Filippa M, Devouche E, Arioni C, Imberty M, Gratier M. Live maternal speech and singing have beneficial effects on hospitalized preterm infants. Acta Paediatr. 2013 Oct;102(10):1017-20. [PubMed] DOI: 10.1111/apa.12356

30. Rand K, Lahav A. Maternal sounds elicit lower heart rate in preterm newborns in the first month of life. Early Hum Dev. 2014 Oct;90(10):679-83. [PubMed] DOI: 10.1016/i.earlhumdev.2014.07.016

31. Cowen R, Stasiowska MK, Laycock H, Bantel C. Assessing pain objectively: the use of physiological markers. Anaesthesia. 2015 Jul;70(7):828-47. [PubMed] DOI: 10.1111/anae. 13018

32. Eskandari N, Keshavarz M, Jahdi F. The factors affecting physiological responses of premature neonates to Quran recitation. J Qom Univ of Med Sci. 2010;5(3):19-25.

33. Carr D, Elissa Charbonneau D, Tedra Cleveland M, Senelick RC, Stillo J. Non-pharmacological pain management interventions. 2019.

34. Rajan D, Lakshmanan G, Gupta SK, Sivasubramanian R, Saxena A, Juneja R. Effect of Recorded Maternal Voice on Child's Cooperation During Cardiac Catheterization - A randomized controlled trial. Indian Pediatr. 2017 Mar 15;54(3):204-207. [PubMed] DOI: 10.1007/s13312-017$\underline{1031-4}$ 